\title{
CHYLOTHORAX IN INFANCY AND CHILDHOOD
}

\author{
A METHOD OF TREATMENT*
}

\author{
BY \\ IAN KIRKLAND \\ Department of Surgical Paediatrics, Western General Hospital, Edinburgh, Scotland
}

Chylothorax is a rare condition at any age, but especially so in childhood. It has been recognized as a clinical entity since the first report by Asellius in 1627-1628. Accumulations of chyle in the thorax occur at three periods in life: the neonatal, in childhood, and in adult life.

(1) In the neonatal period, what has been called 'spontaneous chylothorax' has probably rightly been referred to as congenital chylothorax in an excellent review by Randolph and Gross (1957). In very few instances can any aetiological factor be found, though possible birth trauma, convulsions, or respiratory obstruction may play a part It is possible, however, as less than 20 cases have so far been recorded, that some underlying abnormality of the lymphatic system must predispose to the development of chylothorax. I would therefore support the terminology of congenital chylothorax. The majority of reported cases have a right-sided effusion, there are a few on the left side, and only one bilateral case so far.

(2) In childhood, the most common aetiological factor is trauma, as a result of penetrating injuries or following operations on the heart and great vessels. Reports of spontaneous chylothorax in this group are exceedingly rare, and I have only been able to find references to three cases-two at just over 2 months of age and one at $2 \frac{1}{2}$ years. The case report following therefore now adds one more to this group. It appears that these rare cases could be called congenital, as it is likely that the underlying cause is a congenital abnormality of the lymphatic system.

(3) In adult life, trauma, neoplasm, and inflammatory obstruction to the lymphatic system all play their part.

At all ages trauma to the thoracic duct is the principal cause of chylous effusions. The traumatic agent in childhood is fairly clear cut, whether it be accidental or operative. Detailed study of the

\footnotetext{
* A paper read at a meeting of the British Association of Paediatric Surgeons in Rotterdam, September 1964.
}

lymphatic system and its possible anomalies offer the best hope of defining precisely the other most common cause of chylothorax at this age period. Experimental chylothorax has been produced in a number of experimental animals by occlusion of the superior vena cava (Blalock, Cunningham, and Robinson, 1936). It is convenient, therefore, to summarize the aetiological factors.

\section{Aetiological Factors}

A. Traumatic. (a) Operative. (b) Non-operative, i.e. penetrating wounds; crushing wounds; blast injuries; coughing; and spinal hyperextension-falls, diving, convulsions.

B. Non-traumatic. (a) Mediastinal malignancy - primary or metastatic of the thoracic duct or lymph glands. (b) Mediastinal infection, e.g. tuberculosis, filariasis. (c) Occasional erosions from aneurysms etc. or superior vena cava thrombosis. (d) Congenital abnormalities of the lymphatic ducts.

\section{Embryology and Anatomy}

The lymphatic system is closely related to, and develops concurrently with, the venous system and, like it, acts as a channel for the return of fluid from the tissues.

Two conflicting concepts of the origin of the lymphatic system are as follows.

(1) All lymphatic channels are developed as outgrowths of the venous endothelium in 6 areas: 2 jugular lymph sacs; 2 iliac lymph sacs; 1 retroperitoneal lymph sac; and cisterna chyli. They invade the tissues by continuous growth and branching. The original connexions with veins may or may not remain as channels in the adult system (Sabin, 1902).

(2) Kampmeier (1912-13) and Huntington (1914) believe that the lymphatic system arises by confluence of perivenous mesenchymal spaces to form larger spaces, and these in turn become confluent to form 
continuous vessels, opening eventually into the venous system.

Whichever is true, in the human embryo lymphatic spaces, the jugular lymph sacs in particular are seen at the $10-11 \mathrm{~mm}$. stage. Two channels, right and left, with numerous cross anastomoses form a plexus of lymphatic vessels along the course of the aorta. Sabin reports the first appearance of the cisterna chyli in $23 \mathrm{~mm}$. human embryos. The thoracic duct is first found in human embryos of $24 \mathrm{~mm}$. and by $30 \mathrm{~mm}$. is complete.

In a carefully documented study, Davis (1914-15) divides the 'adult pattern' of thoracic ducts into 9 potential groups and has found evidence of all but 2 of these in dissected specimens. There are many variations in pattern, and what the anatomists consider the normal description was only present in $63 \%$ of his series of 22 dissections, and a cisterna chyli in only $50 \%$.

Further anatomical studies by Van Pernis (1949) and Anson (1950), and investigation of the free lymphatic venous collateral circulation by Lee (1922), emphasize the many variations in the structure of the lymphatic system in humans.

The thoracic duct is responsible for transferring chyle to the venous system, particularly is it the route through which unsplit fat travels (Frazer, 1943). CoTui, Barcham, and Shafiroff (1944) demonstrated that it was an important route for the transfer of mobilized protein from body depots after haemorrhage. Vitamin $\mathrm{K}$ transfer from the intestine is by this route, and lymphocytes are carried to the bloodstream by the thoracic duct.

Reports of anomalies of the lymphatic system in childhood are few. There are 4 necropsy reports in infants who died as a result of congenital chylothorax: in none of these was a thoracic duct demonstrated (Stewart and Linner, 1926; Hilgenberg, 1929; Everhart and Jacobs, 1939; Forbes 1944).

\section{Clinical Features}

The clinical picture is fairly clear cut in the majority of patients. There is respiratory distress, evidence of pleural effusion, usually unilateral, and a possible history of trauma, either operative or nonoperative. In the newborn there are symptoms and signs of respiratory distress which is associated with a pleural effusion. In patients with other evidence of lymphatic anomalies the possibility of chylous extravasation must be always kept in mind. Again respiratory symptoms, unassociated with pyrexia and possibly accompanied by nutritional inadequacy, should lead one to the diagnosis. The diagnosis is confirmed by aspiration of the chylous effusion, characterized by its milky appearance, sterility on culture, lack of odour, alkaline reaction, s.G. greater than 1.012 , high protein content usually 1-6 g./100 ml., high fat content $(0 \cdot 4-40 \mathrm{~g} . / 100 \mathrm{ml}$.), lymphocytic predominance in leucocyte count, and separation into two distinct layers on standing.

\section{Treatment}

Treatment can be summarized as conservative or operative. Conservative treatment consists of regular emptying of the pleural cavity by aspiration, with supportive general treatment with a high protein, high split-fat diet, with the fat soluble vitamin supplements especially vitamin $K$. Because of the bacteriostatic properties of chyle (Lampson, 1948; Whitcomb and Scoville, 1942), infection in the pleural cavity as a result of repeated aspiration is most unlikely. Plasma infusions may be necessary if large quantities of effusion continue to be aspirated.

Intravenous reinfusion of aspirated chyle was introduced by Oeken (1908) and has been tried subsequently by Bauersfeld (1937), Little, Harrison, and Blalock (1942), Peet and Campbell (1943), and Schnug and Ransohoff (1943), but this has been associated with unexplained sudden death.

There have been numerous reported survivors, both in neonatal patients and in those with postoperative chylothorax, as a result of vigorous conservative treatment, the chylous effusion suddenly ceasing and the patients remaining well (Maloney and Spencer, 1956; Boles and Izant, 1960).

Operative treatment consists of controlling, by direct suture or thoracic duct ligation above and below, the points of leakage after identifying the fistulae. Cauterization or irritation of the mediastinal pleura to produce post-operative visceroparietal adhesions is often added. Opinion is divided sharply between those who advocate early or delayed operative treatment, but when there is obvious deterioration in the patient, particularly from a nutritional point of view, in spite of adequate supportive therapy, then operation becomes imperative. There has been little mortality and considerable success with operative treatment during the past few years (Burdette, 1959; Shumacker and Moore, 1951; Randolph and Gross, 1957).

As a result of experience with CSF drainage in hydrocephalus using a Holter valve, and with a similar procedure in treating ascites (Smith, Preshaw, and Bisset, 1962), it seemed worth considering this method of treatment in a patient with progressive bilateral chylothorax, in whom nutritional and respiratory problems were becoming acute. If continuous pleuro-venous drainage could be achieved instead of repeated thoracentesis, then the patient 


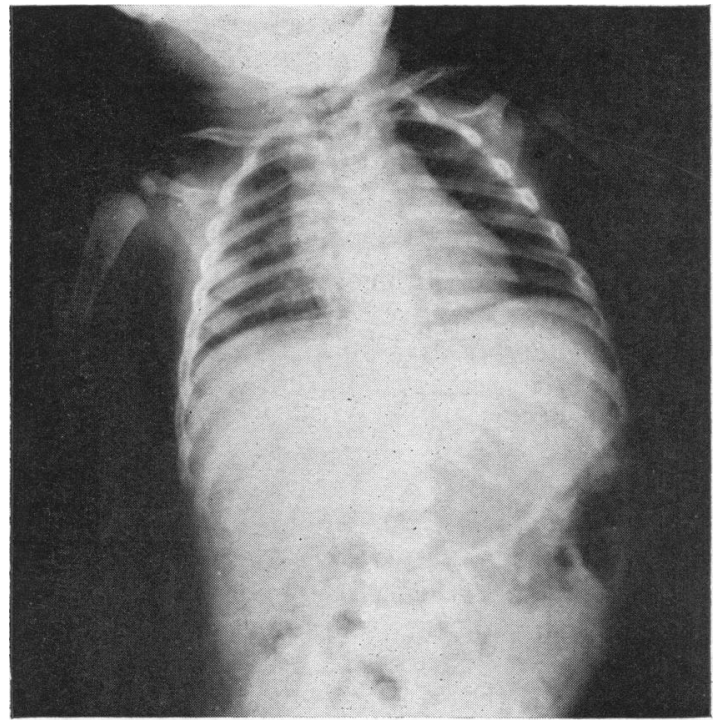

Fig. 1.-Patient aged 4 months. Chest radiograph normal.

could possibly be made fit for more definitive surgery later.

Before operation the aspirated chylous effusion was set up in a burette and allowed to drain continuously through a Holter valve, the maximum height of fluid being $18 \mathrm{in} .(46 \mathrm{~cm}$.) above the valve. Over a

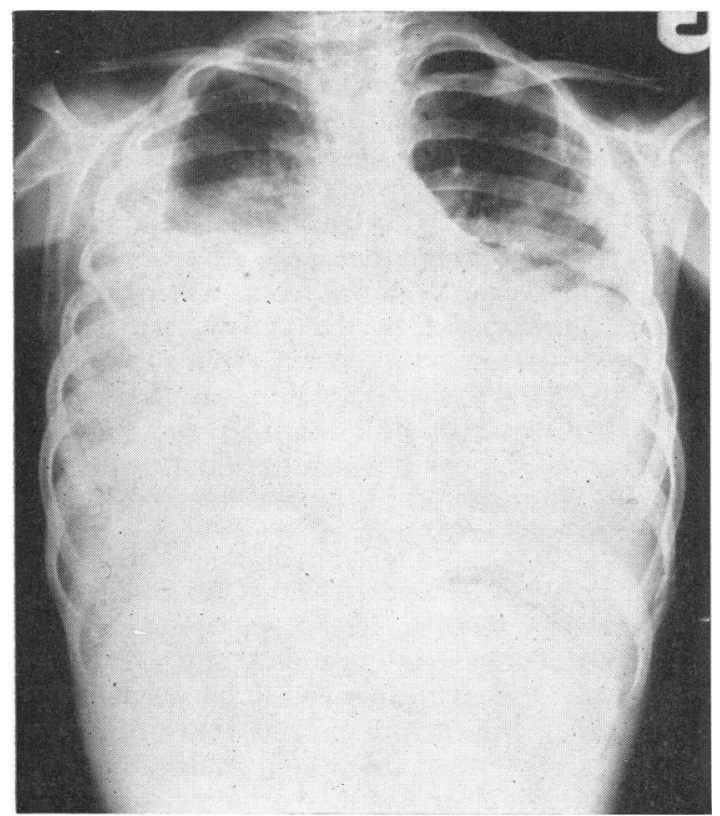

Fig. 2.-Patient aged 3 years and 11 months. Chest radiograph showing right-sided pleural effusion and apparent abdominal swelling. period of 3 days there was no evidence of clot formation or blockage of the valve in spite of the high protein content of the effusion.

The operation consisted essentially of exposing the right eighth and ninth ribs through a small curved mid axillary incision. A moulded 'ventricular' catheter was inserted through the eighth intercostal space by means of an introducer, and attached to a low pressure Holter valve which was anchored to the ninth rib by silk sutures along its length, so that the valve could be compressed against the rib. Chyle drained through the catheter and valve. A separate subinguinal incision exposed the right long saphenous vein. After ligature of its tributaries and the main trunk itself, a silicone rubber tube, previously attached to the distal end of the Holter valve and led to the inguinal region through a subcutaneous tunnel, was introduced through the long saphenous vein into the femoral vein, external iliac vein, and finally into the inferior vena cava. Its position was checked radiologically. Thus a continuous pleurovenous shunt incorporating a Holter valve to allow flow in only one direction was achieved.

\section{Case Report}

A 7 lb. 12 oz. (3,515 g.) girl was born on May 15, 1957 after an assisted forceps delivery for delay in the second stage of labour. The mother was under treatment for pulmonary tuberculosis. At birth the baby was found to be normal except for a swelling on the medial aspect of the right thigh, diagnosed as a lymphangioma with some lymphoedema of the right leg, its bulk being $50 \%$ greater than the left. At the age of 1 month lymphangiograms of the right leg were undertaken with patent blue. These indicated a delay in lymph drainage from the toes of the right foot, with generalized spread of dye throughout the body before filling of the lymphangioma of the thigh. Removal of the lymphangioma was therefore undertaken at the age of 6 weeks. BCG vaccination was given before the baby went home, and thereafter the Heaf test was positive. The baby was under constant surveillance over the next $3 \frac{1}{2}$ years (Fig. 1), and had to be admitted to hospital on numerous occasions for control of the lymphoedema, for episodes of infection, and for fractures of the right leg. Throughout this time her general health was excellent. At the age of 4 years she was admitted to hospital suffering from respiratory symptoms, loss of weight, and general unwellness, and, because of the family history, pulmonary tuberculosis was suspected. A rightsided pleural effusion (Fig. 2) was found, which on aspiration proved to be chylous. On admission to the Surgical Paediatric Unit at the Western General Hospital for further investigation, she was a pale, thin, undernourished child, with an irritant non-productive cough, and variable breathlessness particularly at night. She could only sleep when kept upright on pillows. Her appetite was poor, but she had no other general symptoms. She had been confined to bed for several weeks. 
On examination she was apyrexial with no evidence of lymphadenopathy, finger clubbing, or koilonychia. There was gross lymphoedematous swelling of the right leg extending suprapubically and into the vulva. There was some degree of protuberance of the abdomen without prominent veins and a soft fluctuant mass in the right renal area subcutaneously. The fluid in the limb was compressible and could be shifted from compartment to compartment along its length. There was evidence of pleural effusion on both sides, the right side being more extensive than the left.

Radiographs confirmed the presence of bilateral pleural effusions (Fig. 3).

Laboratory findings. Blood count normal. Plasma proteins $6.75 \mathrm{~g} . / 100 \mathrm{ml}$, albumin $4 \cdot 20$; globulin 2.55 . Serum cholesterol $250 \mathrm{mg} . / 100 \mathrm{ml}$.

Urinalysis, normal, no chyle.

Aspirate from right pleural cavity, $500 \mathrm{ml}$. Total protein $4.25 \mathrm{~g}$./100 ml.; cholesterol $425 \mathrm{mg}$./ $100 \mathrm{ml}$; ; total fat 710 $\mathrm{mg} . / 100 \mathrm{ml}$. Electrophoretic pattern, virtually that of plasma except for absence of fibrinogen. Culture sterile. Cells, occasional WBC, RBC, and debris; s.G. 1.014; $p \mathrm{H}, 8-9$; sugar, negative.

Progress. Owing to respiratory distress, chest aspiration was necessary at intervals of a few days and amounts of chylous effusion from $500 \mathrm{ml}$. to $1,300 \mathrm{ml}$. were obtained, with a composition similar to the original specimen. Larger and larger aspirates were necessary to relieve the respiratory distress. It was noted both clinically and radiologically that aspiration of the right pleural cavity reduced the effusion on the left side (Fig. 4).

During this time a high protein supplemented diet with 'complan' was administered, but in spite of this the child's condition did not improve and the plasma proteins fell to a total of $4.25 \mathrm{~g} . / 100 \mathrm{ml}$., albumin $2.60 \mathrm{~g} . / 100 \mathrm{ml}$., and globulin $1.65 \mathrm{~g} . / 100 \mathrm{ml}$, , necessitating a plasma transfusion.

Spontaneous cutaneous fistulae were noted at the vulva when large quantities of chylous fluid leaked for some hours intermittently.

Treatment to relieve the respiratory embarrassment and to improve her general condition seemed imperative, and operation was undertaken 6 weeks after admission. This consisted of a continuous pleuro-venous anastomosis incorporating a low pressure Holter valve (Fig. 5). The child withstood the operative procedure well, and the Holter valve continued to function. Drainage of the chylous effusion was assisted by regular 'pumping' of the valve.

Air entry into both lung fields remained adequate, but continued reaccumulation of chylous effusion required aspiration of the right pleural cavity $(1,350 \mathrm{ml}$.) on the eighth post-operative day. She was able to get up in a chair for short periods without respiratory distress. Further aspiration of $1,200 \mathrm{ml}$. from the right pleural cavity was necessary a few days later, and regular 'pumping' of the valve was continued.

There was some improvement in her general condition, and air entry to both lungs remained adequate. Twenty

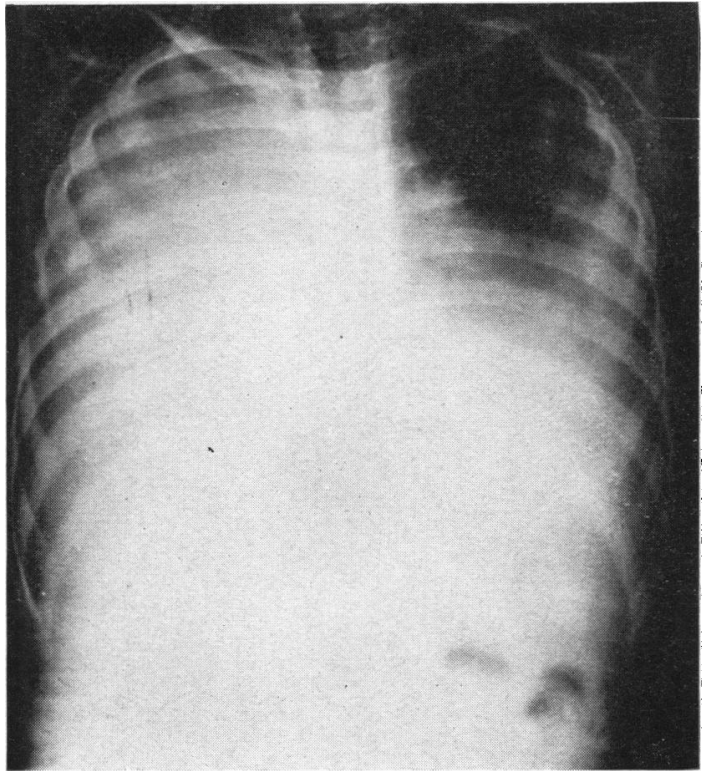

Fig. 3.-Patient aged 4 years and 1 month. Bilateral pleural effusion.

days after operation, while she was having attention to the skin of her buttocks, she died suddenly.

Necropsy the following day confirmed the presence of chylous effusion in both pleural cavities. This came from multiple fistulae along the lower half of the mediastinal pleura and along the attachments of the diaphragm to the lateral aspects of the vertebral bodies. These fistulae

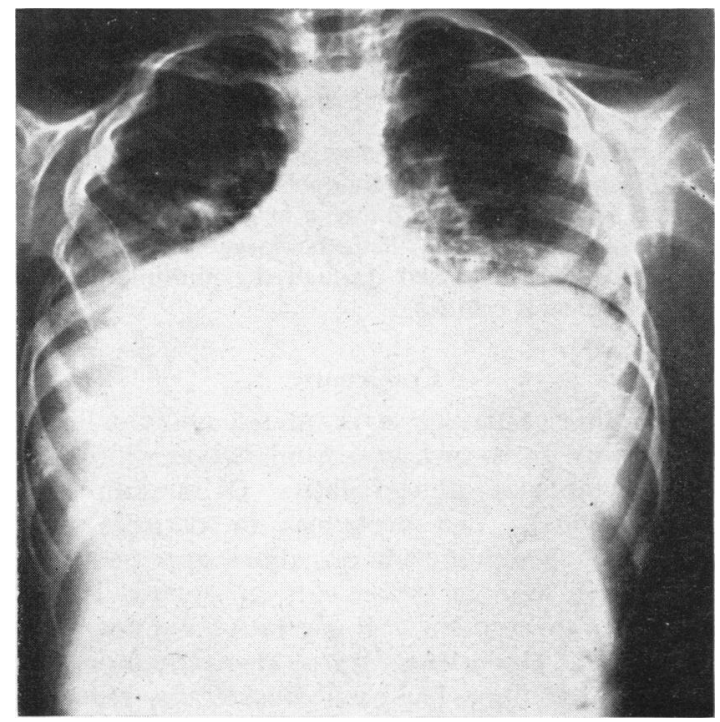

FIG. 4.-Patient two weeks after Fig. 3. Aspiration of right pleural cavity only, showing bilateral improvement. 


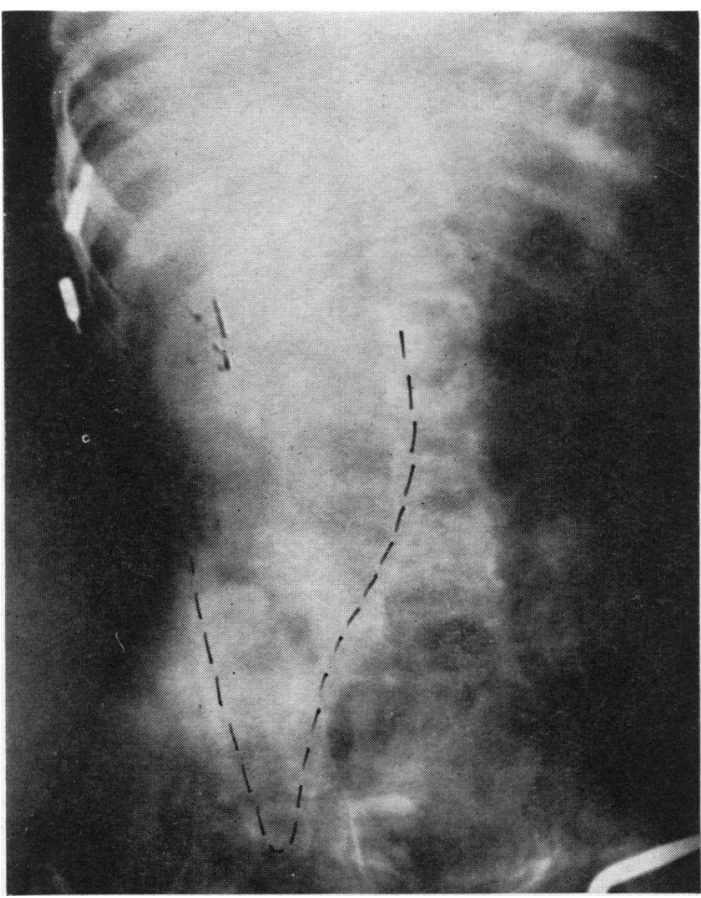

Fıg. 5.-Shows Holter valve in position and siliconed rubber tube leading into inferior vena cava to the level of $L 1$.

communicated with large mediastinal lymph spaces which in turn communicated with large dilated retroperitoneal lymphatic channels. There was no chylopericardium or dilated mesenteric lacteals. The amount of chyloperitoneum was minimal and could have been produced at necropsy. The other abdominal organs were unaffected. The large dilated lymphatics in both lower limbs and perineum were confirmed.

No thoracic duct was identified at first, but later multiple mediastinal lymph channels were identified. Dye injected shortly after death into a large lymphatic space in the inguinal region filled the large retroperitoneal lymph spaces and passed through the multiple fistulae into both pleural cavities.

\section{Comments}

Chylothorax may occur in infancy and childhood as an entity on its own or in conjunction with other gross lymphatic abnormalities (Kinmonth and Taylor, 1964). The prognosis in patients with widespread lymphatic abnormalities appears to be more grave than in those with an isolated lesion. With the improvement in conservative and operative treatment of chylothorax on its own, the mortality from this condition has been considerably reduced.

There are still patients whose general health continues to deteriorate in spite of adequate conserv- ative treatment, and others in whom gross congenital abnormalities of the rest of the lymphatic system preclude the usual operative measures to control the chylous fistulae. It is for this reason that a new attempt at treatment has been undertaken employing new materials and appliances, and utilizing the pressure differential between the pleural cavity (from $5 \mathrm{~mm} . \mathrm{Hg}$ to atmospheric pressure or more) and the pressure in the inferior vena cava near its entry to the heart (which varies from 0 to $-5 \mathrm{~mm}$. $\mathrm{Hg}$ ).

The incorporation of a valve of the Holter type prevents the reflux of blood into the drainage system. The diminished content of fibrinogen in chyle appears to prevent clotting of the chylous effusion in the drainage system.

\section{Summary}

A brief review of chylothorax is presented with comments on its occurrence, aetiology, clinical features, and treatment.

The embryology and anatomy of the lymphatic system as far as it is known is summarized. Scarcity of available published material detailing congenital anomalies is apparent and further investigation in this field is very necessary.

\section{REFERENCES}

Anson, B. J. (1950). An Atlas of Anatomy. W. B. Saunders, Philadelphia and London.

Asellius, G. (1627-1628). De lactibus, sive lacteis venis, quarto vasorum mesarai coruum genere, novo invento, dissertation, Milan. Leydon, 1640, University Library.

Bauersfeld, E. H. (1937). Traumatic chylothorax from ruptured thoracic duct treated by intravenous injection of aspirated chyle. J. Amer. med. Ass., 109, 16.

Blalock, A., Cunningham, R. S., and Robinson, C. S. (1936). Experimental production of chylothorax by occlusion of the superior vena cava. Ann. Surg., 104, 359.

Boles, E. T., Jr., and Izant, R. J., Jr. (1960). Spontaneous chylothorax in the neonatal period. Amer.J. Surg., 99, 870.

Burdette, W. J. (1959). Management of chylous extravasation. Arch. Surg., 78, 815.

CoTui, Barcham, I. S., and Shafiroff, B. G. P. (1944). Ligation of the thoracic duct and the posthemorrhage plasma protein level. Surg. Gynec. Obstet., 79, 37.

Davis, H. K. (1914-15). A statistical study of the thoracic duct in man. Amer. J. Anat.. 17, 211

Everhart, J. K., and Jacobs, A. H. (1939). Chylothorax: a review of the literature and report of case in newborn infant. J. Pediat., $15,558$.

Forbes, G. B. (1944). Chylothorax in infancy: observations on the absorption of vitamins $A$ and $D$ and on the intravenous replacement of aspirated chyle. ibid., 25, 191.

Frazer, A. C. (1943). Differentiation in the absorption of olive oil and oleic acid in the rat. J. Physiol. (Lond.), 102, 306.

Hilgenberg, F. C. (1929). Ein Fall von Chylothorax beim Neugeborenen. Mschr. Geburtsh. Gvnäk., 83, 225.

Huntington, G. S. (1914). The development of the mammalian jugular lymph sac, of the tributary primitive ulnar lymphatic and of the thoracic ducts. Amer.J. Anat., 16, 259.

Kampmeier, O. F. (1912-13). The development of the thoracic duct in the pig. ibid., 13, 401 .

Kinmonth, J. B., and Taylor, G. W. (1964). Chylous reflux. Brit. med. J., 1, 529.

Lampson, R. S. (1948). Traumatic chylothorax: a review of the literature and report of a case treated by mediastinal ligation of the thoracic duct. J. thorac. Surg., 17, 778.

Lee, F. C. (1922). The establishment of collateral circulation following ligation of the thoracic duct. Bull. Johns Hopk. Hosp., 33. 21. 
Little, J. M., Harrison, C., and Blalock, A. (1942). Chylothorax and chyloperitoneum: Effects of reintroduction of aspirated chyle. Surgery, 11, 392.

Maloney, J. V., Jr., and Spencer, F. C. (1956). The nonoperative treatment of traumatic chylothorax. ibid., 40, 121.

Oeken, H. (1908). Ein Fall von Zerreissung des Ductus thoracicus infolge Brustquetschung. Munch. med. Wschr., 55, 1182.

Peet, M. M., and Campbell, K. N. (1943). Massive chylothorax following splanchnicectomy: treatment with intravenous and intrasternal transfusions of chyle. Univ. Hosp. Bull. mich., 9, 2.

Randolph, J. G., and Gross, R. E. (1957). Congenital chylothorax. Arch. Surg., 74, 405.

Sabin, F. R. (1902). On the origin of the lymphatic system from the veins and the development of the lymph hearts and thoracic duct in the pig. Amer.J. Anat., 1, 367.
Schnug, E., and Ransohoff, J. (1943). Traumatic chylothorax-a case treated with intravenous chyle. Surgery, 14, 278.

Shumacker, H. B., Jr., and Moore, T. C. (1951). Surgical management of traumatic chylothorax. Surg. Gynec. Obstet., 93, 46.

Smith, A. N., Preshaw, R. M., and Bisset, W. H. (1962). The drainage of resistant ascites, by a modification of the Spitz-Holter valve technique. J. roy. Coll. Surg. Edinb., 7, 289.

Stewart, C. A., and Linner, H. P. (1926). Chylothorax in the newborn infant-report of a case. Amer.J. Dis. Child., 31, 654.

Van Pernis, P. A. (1949). Variations of the thoracic duct. Surgery, 26, 806.

Whitcomb, B. B., and Scoville, W. B. (1942). Postoperative chylothorax: sudden death following the infusion of aspirated chyle. Arch. Surg., 45, 747. 